\title{
PENCEGAHAN LUKA TEKAN MELALUI PIJAT MENGGUNAKAN VIRGIN COCONUT OIL
}

\author{
Ririn Sri Handayani ${ }^{1,2^{*}}$, Dewi Irawaty ${ }^{3}$, Ria Utami Panjaitan ${ }^{3}$ \\ 1. Jurusan Keperawatan Poltekkes Kemenkes Tanjung Karang Lampung, Sumatera Selatan 35144, Indonesia \\ 2. Program Studi Magister Fakultas Ilmu Keperawatan Universitas Indonesia, Depok 16424, Indonesia \\ 3. Fakultas Ilmu Keperawatan Universitas Indonesia, Depok 16424, Indonesia \\ *Email: ririnsrihandayani@yahoo.com
}

\begin{abstract}
Abstrak
Penelitian ini merupakan penelitian kuantitatif dengan desain quasi eksperimen post test only yang bertujuan untuk membuktikan efektifitas pencegahan luka tekan grade I menggunakan $V C O$ dengan pijat pada klien yang berisiko mengalami luka tekan di Unit Bedah, Rumah Sakit AB, Provinsi Lampung. Hasil uji Fisher exact dan regresi logistik berganda menunjukkan adanya perbedaan kejadian luka tekan pada klien yang dirawat menggunakan $V C O$ dengan pijat dibandingkan dengan klien yang dirawat tanpa $V C O(\mathrm{p}=0,033 ; \alpha=0,05 ; \mathrm{OR}=0,733 ; 95 \% \mathrm{CI} 0,540-0,995)$ setelah dikontrol oleh variabel Indeks Massa Tubuh (IMT). Disarankan kepada perawat agar dapat melakukan pijat menggunakan $V C O$, sebagai salah satu intervensi mandiri keperawatan dalam intervensi pencegahan luka tekan pada klien yang berisiko mengalami luka tekan.
\end{abstract}

Kata Kunci: efektivitas pencegahan, luka tekan derajat I, VCO

\begin{abstract}
This study is a quantitative research design with quasi experiments post test only that aim to prove the effectiveness of prevention pressure ulcer grade I using VCO with a massage on clients at risk of developing pressure ulcer at Surgical Unit, $A B$ Hospital, Lampung Province. The results of Fisher exact test and multiple logistic regression showed a difference in the incidence of pressure ulcer on clients who were treated using VCO with a massage than clients who were treated without $\operatorname{VCO}(p=0,033 ; \alpha=0,05 ; O R=0,733 ; 95 \%$ CI 0,540-0,995) after controlled by variable body mass index (BMI). It is recommended to nurses in order to do massage using $V C O$, as one of the nursing independent intervention in pressure ulcer prevention interventions on clients at risk of developing pressure ulcer.
\end{abstract}

Keywords: the effectiveness of prevention, grade I pressure ulcer, VCO

\section{Pendahuluan}

Luka tekan adalah injury terlokalisir pada kulit dan atau jaringan yang dibawahnya ada tulang yang menonjol (bony prominence), sebagai akibat dari tekanan atau kombinasi tekanan dengan regangan dan atau gesekan. Epidemiologi luka tekan bervariasi di beberapa tempat, insiden berkisar antara 0,4\% $38 \%$ di unit perawatan akut, $2,2 \%-28 \%$ di unit perawatan jangka panjang, $0 \%-29 \%$ diperawatan rumah (Lyder, 2003 dalam Reddy, Gill, \& Roccon, 2006; Ayello, 2007).

Prevalensi luka tekan di RS Dr. Sardjito Yogyakarta menurut Purwaningsih (2001) dalam Fitriyani (2008) sebesar 40\%. Laporan mutu RS Abdul Moeloek Lampung 2009 menunjukkan rata-rata angka kejadian luka tekan periode November - Desember 2009 di Unit Bedah pada ruangan Mawar 0,5, Kutilang $12,87 \%$, dan Gelatik 0,45.

Peran perawat dalam upaya pencegahan luka tekan menurut Potter dan Perry (2005) ada tiga area intervensi keperawatan utama. Intrevensi tersebut merupakan perawatan kulit yang meliputi perawatan hygiene dan pemberian topical; pencegahan mekanik dan dukungan permukaan yang meliputi penggunaan tempat tidur, pemberian posisi dan kasur terapeutik; dan edukasi.

Virgin Coconut Oil (VCO) merupakan minyak kelapa yang dihasilkan dari proses pengolahan daging buah kelapa tanpa melakukan pemanasan, 
atau melalui pemanasan dengan suhu rendah sehingga menghasilkan minyak dengan warna yang jernih, tidak berbau tengik dan terbebas dari radikal bebas akibat pemanasan. Syah (2005) dalam Lucida, et al. (2008) menyatakan bahwa VCO mengandung 92\% asam lemak jenuh yang terdiri dari $48-53 \%$ asam laurat, 1,5-2,5\% asam oleat, asam lemak lainnya seperti $8 \%$ asam kaprilat, dan $7 \%$ asam kaprat. Siswono (2006) menyatakan bahwa VCO diyakini baik untuk kesehatan kulit karena mudah diserap kulit dan mengandung vitamin $\mathrm{E}$.

Upaya pencegahan luka tekan di Rumah Sakit Dr. H. Abdoel Moeloek Bandarlampung khususnya di Unit Bedah dilakukan melalui edukasi klien dan keluarga dan tindakan keperawatan langsung berupa alih baring setiap dua jam. Penggunaan pelembab belum distandarisasi dan umumnya klien dianjurkan untuk memakai body lotion atau minyak goreng yang dimiliki.

Berdasarkan kandungan $V C O$ dan manfaatnya bagi perawatan kulit, peneliti tertarik untuk melakukan penelitian tentang efektifitas penggunaan $V C O$ dengan pijat untuk pencegahan luka tekan pada klien yang berisiko mengalami luka tekan di Rumah Sakit AB, Provinsi Lampung.

\section{Metode}

Desain penelitian ini adalah Quasi-experimental dengan post-test only. Pada penelitian terdapat kelompok intervensi dan kelompok kontrol. Kelompok perlakuan diberi perawatan pencegahan standar yaitu miring kiri kanan 30 derajat tiap dua jam, mandi 2 kali sehari dan $V C O$ dengan pijat ringan berupa efflurage 4-5 menit (Elliz \& Bentz, 2007) di daerah skapula, sacrum, dan tumit sedangkan kelompok kontrol mendapat perawatan pencegahan standar saja yaitu miring kiri kanan 30 derajat tiap dua jam, mandi dua kali sehari.

Populasi penelitian adalah semua klien yang berisiko mengalami luka tekan di tiga ruangan pada Unit Bedah Rumah Sakit AB Propinsi Lampung yaitu Ruang Mawar, Ruang Kutilang, dan Ruang Gelatik. Sampel berjumlah 33 orang dihitung dengan rumus uji beda dua proporsi dari Lameshow (1990) dengan power uji $80 \%$. Sampel terbagi menjadi 15 untuk kelompok kontrol dan 18 untuk kelompok intervensi.

Teknik pengambilan sampel menggunakan metode purposive sampling dan penentuan sampel masuk kedalam kelompok intervensi atau kontrol dilakukan dengan cara random sederhana. Jumlah sampel keseluruhan adalah 33 sampel.

Tabel 1. Distribusi Frekuensi Responden Berdasarkan Usia

\begin{tabular}{lccccc}
\hline \multicolumn{1}{c}{ Variabel } & Mean & Median & $\begin{array}{c}\text { Standar Deviasi } \\
\text { (SD) }\end{array}$ & Min - Maks & 95\% CI \\
\hline Usia & & & & & \\
Kelompok Intervensi & 38,78 & 28,50 & 21,218 & $18-89$ & $28,23-49,33$ \\
Kelompok Kontrol & 39,07 & 35,00 & 17,086 & $16-73$ & $29,60-48,53$ \\
\hline
\end{tabular}

\section{Hasil}

\section{Karakteristik responden}

Distribusi frekuensi responden berdasarkan pada karakteristik usia tersaji dalam tabel 1. Pada kelom pok intervensi rata-rata usia responden 38,78 tahun ( $\mathrm{SD}=21,218)$, usia termuda 18 tahun dan paling tua 89 tahun.
Hasil estimasi interval diyakini $95 \%$ rata-rata usia responden kelompok intervensi 28,23 hingga 49,33 tahun. Pada kelompok kontrol rata-rata usia responden 39,07 tahun dengan standar deviasi 17,086, usia termuda 16 tahun dan paling tua 73 tahun. Dari hasil estimasi interval 95\% rata-rata usia responden kelompok kontrol 29,60 hingga 48,53 tahun. 
Distribusi frekuensi responden berdasarkan pada karakteristik jenis kelamin yang tersaji dalam tabel 2 . Pada kelompok intervensi $88,9 \%$ berjenis kelamin laki-laki dan $11,1 \%$ berjenis kelamin perempuan. Untuk responden kelompok kontrol $86,7 \%$ berjenis kelamin laki-laki dan 13,3\% berjenis kelamin perempuan. Jumlah keseluruhan responden yaitu 29 orang $(88 \%)$ berjenis kelamin laki-laki dan empat orang $(12 \%)$ berjenis kelamin perempuan dari total responden keseluruhan 33 orang $(100 \%)$.

Karakteristik responden berdasarkan pada diagnosa medis dalam variabel nominal polikotom dianalisis menggunakan analisis deskriptif distribusi frekuensi. Pada tabel 3 menyajikan karakteristik responden berdasarkan diagnosa medis. Jika dilihat sebagian besar responden dalam penelitian adalah klien dengan dignosa medis fraktur.

Karakteristik responden berdasarkan pada kategori risiko luka tekan dalam variabel ordinal dianalisis dengan menggunakan analisis deskriptif distribusi frekuensi. Pada tabel 4 disajikan distribusi frekuensi responden berdasarkan kategori risiko yaitu pada kelompok intervensi, dimana dari 18 responden yang termasuk dalam kategori berisiko mengalami luka tekan menurut skala Braden yaitu sebanyak sembilan orang $(50 \%)$, kategori risiko sedang sebanyak enam $(33,3 \%)$, kategori risiko tinggi sebanyak tiga orang $(16,67 \%)$, dan kategori risiko sangat tinggi tidak ada $(0 \%)$.

Pada kelompok kontrol, yaitu dari 15 responden yang termasuk dalam kategori berisiko mengalami luka tekan menurut skala Braden sebanyak 12 orang $(86,7 \%)$, kategori risiko sedang tidak ada $(0 \%)$, kategori risiko tinggi sebanyak tiga orang $(13,3 \%)$, dan kategori risiko sangat tinggi tidak ada $(0 \%)$.

Karakteristik responden berdasarkan kategori IMT dianalisis dengan menggunakan analisis deskriptif distribusi frekuensi yang disajikan dalam tabel 5 . Pada kelompok intervensi diketahui bahwa rata-rata IMT responden $20,02 \mathrm{~kg} / \mathrm{m}^{2}$ dengan standar deviasi 3,98 , IMT terendah $10,5 \mathrm{~kg} / \mathrm{m}^{2}$ dan IMT tertinggi $24 \mathrm{~kg} / \mathrm{m}^{2}$.

Tabel 2. Distribusi Frekuensi Responden Berdasarkan Jenis Kelamin

\begin{tabular}{rlcccccc}
\hline \multirow{2}{*}{ Variabel } & \multirow{2}{*}{ Kategori } & \multicolumn{2}{c}{ Kelompok Intervensi } & \multicolumn{2}{c}{ Kelompok Kontrol } & \multicolumn{2}{c}{ Jumlah } \\
\cline { 3 - 7 } & & $\mathbf{n}$ & $\boldsymbol{\%}$ & $\mathbf{n}$ & $\boldsymbol{\%}$ & $\mathbf{n}$ & $\boldsymbol{\%}$ \\
\hline \multirow{2}{*}{ Jenis Kelamin } & \multirow{2}{*}{ Laki-laki } & 16 & 88,9 & 13 & 86,7 & 29 & 88 \\
& Perempuan & 2 & 11,1 & 2 & 13,3 & 4 & 12 \\
\hline
\end{tabular}

Berdasarkan hasil estimasi interval menunjukkan bahwa 95\% rata-rata IMT responden kelompok intervensi yaitu sebesar 18,04 hingga 21,99 kg/m². Sedangkan pada kelompok kontrol rata-rata IMT responden yaitu $25,51 \mathrm{~kg} / \mathrm{m}^{2}$ dengan standar deviasi 1,23 , dengan IMT terendah $24 \mathrm{~kg} / \mathrm{m}^{2}$ dan paling tinggi $27,55 \mathrm{~kg} / \mathrm{m}^{2}$. Berdasar hasil estimasi interval $95 \%$ rata-rata IMT responden kelompok kontrol 24,83 hingga $25,19 \mathrm{~kg} / \mathrm{m}^{2}$.

Distribusi frekuensi responden berdasarkan riwayat merokok yang tersaji dalam tabel 6. Pada kelompok intervensi dari 18 responden yang tidak merokok sebanyak enam orang $(33,3 \%)$, merokok sebanyak
12 orang $(66,7 \%)$. Pada kelompok kontrol, yaitu dari 15 responden yang tidak merokok sebanyak enam orang $(40 \%)$, merokok sebanyak sembilan orang $(60 \%)$.

Kejadian luka tekan Grade I Non Blanchable Erytema dalam bentuk data proporsi ditampilkan dalam tabel 7. Pada tabel tersebut menyajikan gambaran proporsi kejadian luka tekan grade I pada kelompok intervensi dan kelompok kontrol. Pada kelompok intervensi, yaitu dari 18 responden proporsi kejadian luka tekan grade I sebanyak 0 (nol) $(0 \%)$ atau 18 responden $(100 \%)$ yang tidak mengalami luka tekan grade I selama masa penelitian. 
Tabel 3. Distribusi Frekuensi Responden Berdasarkan Diagnosa Medis

\begin{tabular}{|c|c|c|c|c|c|c|c|}
\hline \multirow{2}{*}{ Variabel } & \multirow{2}{*}{ Kategori } & \multicolumn{2}{|c|}{$\begin{array}{l}\text { Kelompok } \\
\text { Intervensi } \\
\end{array}$} & \multicolumn{2}{|c|}{$\begin{array}{c}\text { Kelompok } \\
\text { Kontrol } \\
\end{array}$} & \multicolumn{2}{|c|}{ Jumlah } \\
\hline & & $\mathbf{n}$ & $\%$ & $\mathbf{n}$ & $\%$ & $\mathbf{n}$ & $\%$ \\
\hline \multirow{12}{*}{$\begin{array}{l}\text { Diagnosa } \\
\text { Medis }\end{array}$} & Cedera Kepala & 1 & 5,6 & 1 & 6,7 & 2 & 6,1 \\
\hline & Post Op Apendik Perforasi + Peritonitis & & & 1 & 6,7 & 1 & 3 \\
\hline & Fraktur Femur dg Traksi & 2 & 11 & 1 & 6,7 & 3 & 9 \\
\hline & Fraktur Femur + Tibia & 3 & 16,7 & 1 & 6,7 & 4 & 12,1 \\
\hline & Fraktur Femur & 4 & 22,2 & 2 & 13,3 & 6 & 18,2 \\
\hline & Fraktur Tibia + Traksi & 3 & 16,7 & 2 & 13,3 & 5 & 15,2 \\
\hline & Cedera Spinal & 2 & 11 & 1 & 6,7 & 3 & 9 \\
\hline & Post Amputasi Tibia-Fibula & & & 1 & 6,7 & 1 & 3 \\
\hline & Abses Abdomen & & & 1 & 6,7 & 1 & 3 \\
\hline & Ileus + Susp Ca. Colon & 1 & 5,6 & 1 & 6,7 & 2 & 6,1 \\
\hline & Post Op Nefroli thotomi & 1 & 5,6 & 1 & 6,7 & 2 & 6,1 \\
\hline & Post Op Craniotomi & 1 & 5,6 & 2 & 13,3 & 3 & 9 \\
\hline
\end{tabular}

Pada kelompok kontrol, dari 15 responden selama masa penelitian ada 4 (empat) orang $(26,67 \%)$ responden yang mengalami luka tekan grade I dan 11 orang $(73,33 \%)$ tidak mengalami luka tekan grade $\mathrm{I}$.

\section{Perbedaan Kejadian Luka Tekan Grade I pada Kelompok dengan $\mathrm{VCO}$ dan Tanpa $\mathrm{VCO}$}

Hasil penelitian menunjukkan bahwa terdapat perbedaan yang bermakna terhadap kejadian luka tekan grade I antara responden yang diberikan perawatan pencegahan menggunakan $V C O$ dengan pijat dan tanpa $V C O(\mathrm{p}=0,033 ; \alpha=0,05 ; \mathrm{RR}=$ 0,733; 95\% CI 0,540 - 0,995) (lihat pada tabel 8). Dengan demikian artinya responden yang diberi perawatan dengan $V C O$ terlindungi sebesar 0,733 kali dari kejadian luka tekan grade I dibandingkan dengan responden yang dirawat tanpa menggunakan VCO.

\section{Pembahasan}

Intervensi perawatan untuk mencegah terjadinya luka tekan pada klien yang teridentifikasi berisiko merupakan kewajiban perawat. Upaya tersebut dilakukan sedini mungkin sejak klien teridentifikasi berisiko (Rest Haven, 2008).

Terkait dengan intervensi keperawatan untuk pencegahan luka tekan, Potter dan Perry (2005) menyatakan bahwa terdapat tiga area intervensi keperawatan utama dalam pencegahan luka tekan yakni (pertama) perawatan kulit; meliputi perawatan hygiene dan pemberian topikal, (kedua) pencegahan mekanik dan dukungan permukaan yang meliputi penggunaan tempat tidur, pemberian posisi, dan kasur terapeutik, dan (ketiga) edukasi.

Rekomendasi National Guideline Clearinghouse $(N G C)$ and Institute for Clinical Systems Improvement (ICSI) (2007) untuk meminimalkan gesekan dan shear yang dapat menyebabkan penurunan toleransi jaringan dan mendukung terjadinya luka tekan adalah melakukan tindakan sebagai berikut; secara teratur gunakan pelumas dari minyak hypoallergenic, cream atau lotion pada permukaan kulit yang tertekan, lumasi atau taburi bedak pada bedspan sebelum digunakan oleh klien, dan melindungi kulit dari kelembaban. 
Tabel 4. Distribusi Frekuensi Responden Berdasarkan Kategori Risiko Luka Tekan

\begin{tabular}{llcccccc}
\hline \multirow{2}{*}{ Variabel } & \multicolumn{1}{c}{ Kategori } & \multicolumn{2}{c}{ Kelompok Intervensi } & \multicolumn{2}{c}{ Kelompok Kon trol } & \multicolumn{2}{c}{ Jumlah } \\
\cline { 2 - 7 } & & $\mathbf{n}$ & $\mathbf{\%}$ & $\mathbf{n}$ & $\mathbf{\%}$ & $\mathbf{n}$ & $\mathbf{\%}$ \\
\hline Kategori & Berisiko & 9 & 50 & 12 & 86,7 & 21 & 62,64 \\
Risiko & Risiko Sedang & 6 & 33,3 & 0 & 0 & 6 & 18,18 \\
& Risiko Tinggi & 3 & 16,67 & 3 & 13,3 & 6 & 0 \\
& Risiko Sangat Tinggi & 0 & 0 & 0 & 0 & 0 \\
\hline
\end{tabular}

Pemberian bahan topikal yang berfungsi sebagai pelembab akan memberikan perlindungan terhadap kulit dari kerusakan.

Menurut pendapat peneliti bahwa minyak hypollergenic seperti yang diisyaratkan oleh $N G C$ dan ICSI di atas dapat diperoleh dari VCO. Proses pembuatan $V C O$ yang diolah dengan minimal pemanasan atau tanpa pemanasan sama sekali dapat menghasilkan minyak kelapa dengan tekstur yang lembut dan berwarna jernih serta beraroma kelapa segar. Cara pengolahan seperti ini diyakini mampu mempertahankan sifat-sifat menguntungkan dari kandungan berbagai asam lemak yang ada pada daging buah kelapa.

Kandungan asam lemak jenuh pada $V C O$ bisa mencapai $92 \%$ yang terdiri dari $48 \%$ - 53\% asam laurat (C12), 1,5 - 2,5\% asam oleat dan asam lemak lainnya, seperti $8 \%$ asam kaprilat (C:8) dan 7\% asam kaprat (C:10) (Syah, 2005 dalam Lucida, Salman, \& Hervian, 2008). Disamping itu, VCO juga mengandung Vitamin E (Amin, 2009). Asam laurat dan oleat dalam $V C O$ bersifat melembutkan kulit selain itu $V C O$ efektif dan aman digunakan sebagai moisturizer untuk meningkatkan hidrasi kulit, dan mempercepat penyembuhan pada kulit (Agero \& Verallo-Rowell, 2004; Lucida, Salman, \& Hervian, 2008). Hal ini sesuai pernyataan Bryant (2007), menjelaskan pelembab mempertahankan hidrasi epidermis sehingga meminimalkan efek dari gesekan dan shear.

Penelitian mengenai pemanfaatan $V C O$ sebagai bahan kosmetik menunjukkan bahwa $V C O$ bagus untuk kulit (Broto dalam Gustia 2009). Selain itu, Siswono (2006) juga menyatakan bahwa VCO diyakini baik untuk kesehatan kulit karena mudah diserap kulit dan mengandung vitamin $\mathrm{E}$.

Rajamohan dan Nevin (2010), menyatakan bahwa hasil penelitiannya terhadap penggunaan $V C O$ secara topikal pada luka buatan tikus percobaan yang dibagi dalam tiga kelompok yaitu satu kelompok sebagai kontrol, satu kelompok diberi perlakuan 0,5 $\mathrm{ml} V C O$ dan satu kelompok diberi 1,0 $\mathrm{ml}$ VCO. Hasil pengamatan setelah 10 hari tampak peningkatan aktivitas enzim antioksidan secara bermakna dan penurunan glutathione serta malondialdehyde, peningkatan secara bermakna proliferasi fibroblast dan neovaskularisasi pada kelompok intervensi dibandingkan dengan kelompok kontrol.

Tabel 5. Distribusi Frekuensi Responden Berdasarkan Indeks Massa Tubuh (IMT)

\begin{tabular}{lccccc}
\hline \multicolumn{1}{c}{ Variabel } & Mean & Median & $\begin{array}{c}\text { Standar Deviasi } \\
\text { (SD) }\end{array}$ & Min - Maks & 95\% CI \\
\hline IMT & & & & & \\
Kelompok Intervensi & 20,02 & 21,28 & 3,98 & $10,5-24,00$ & $18,04-21,99$ \\
Kelompok Kontrol & 25,51 & 25,00 & 1,23 & $24,00-27,55$ & $24,83-25,19$ \\
\hline
\end{tabular}


Rajamohan dan Nevin (2010) menyimpulkan bahwa man faat $V C O$ dikaitkan dengan pengaruh kumulatif dari berbagai komponen biologis aktif yang ada didalamnya. Virgin Coconut Oil dikombinasikan dengan pemakaian secara pijat dapat meningkatkan sirkulasi aliran darah. Meskipun, cara pijat masih kontroversi, namun melakukan pijat yang kuat dan di daerah tonjolan tulang perlu dihindarkan, sedangkan pijat secara ringan di bagian lain diperbolehkan.

Penggunaan $V C O$ dengan pijat tidak hanya dapat meningkatkan relaksasi otot dan meningkatkan sirkulasi, tetapi juga dapat meningkatkan absorbsi kandungan biologis $V C O$ melalui kulit. Molekul medium chain fatty acids (MCFA) yang kecil mudah diabsorbsi permukaan kulit. Efek pelumas yang dimiliki oleh $V C O$ menghindarkan kulit yang dipijat dari cidera gesekan akibat pijat.

Trevithick dan Mitton (1999) dalam penelitiannya menyimpulkan bahwa vitamin E dari $V C O$ yang diberikan secara topical dapat terserap dalam 24 jam. Wang dan Quinn (1999) menyatakan bahwa vitamin $E$ adalah zat yang berfungsi sebagai stabilizer membran sel, melindungi kerusakan sel dari radikal bebas, dan sebagai simpanan lemak dalam organel sel. Selain itu, bahwa VCO mempunyai kemampuan antioksidan, antimikrobial, anti fungi, melindungi kulit dari bahaya radikal bebas dan degenerasi jaringan (Villariba, 2004).

Tabel 6. Distribusi Frekuensi Responden Berdasarkan Kategori Riwayat Merokok

\begin{tabular}{llcccccc}
\hline \multirow{2}{*}{ Variabel } & \multirow{2}{*}{ Kategori } & \multicolumn{2}{c}{ Kelompok In tervensi } & \multicolumn{2}{c}{ Kelompok Kontrol } & \multicolumn{2}{c}{ Jumlah } \\
\cline { 3 - 7 } & & $\mathbf{n}$ & $\boldsymbol{\%}$ & $\mathbf{n}$ & $\boldsymbol{\%}$ & $\mathbf{n}$ & \% \\
\hline Riwayat & Tidak Merokok & 6 & 33,3 & 6 & 40 & 12 & 36,36 \\
Merokok & Merokok & 12 & 66,7 & 9 & 60 & 21 & 63,64 \\
\hline
\end{tabular}

Kulit sehat mempunyai $\mathrm{pH}$ permukaan berkisar 5 (lima), yang dibentuk oleh aktivitas sebum dan mikroba kulit, lingkungan yang melindungi kulit dari bahaya mikroorganisme patogen, tanpa sebum kulit menjadi kering dan retak. Sebum sendiri terdiri dari asam lemak rantai sedang seperti yang ada pada VCO. Penelitian oleh Ogbolu, et al. (2007) yang menerangkan bahwa secara invitro dengan media agar-agar membuktikan $V C O$ dapat digunakan sebagai anti fungi pada candida yang resisten obat, klien dengan kelembaban tinggi karena keringat atau inkontinen bermasalah dengan risiko infeksi jamur pada kulit. Dengan demikian, peneliti berasumsi pemberian $V C O$ secara topikal dapat menghambat infeksi jamur sebagai faktor yang menurunkan resistensi jaringan.

Memberikan pelembab memang bukan intervensi utama untuk mencegah terbentuknya luka tekan. Namun, pencegahan luka tekan hanya melakukan perubahan posisi tanpa upaya mempertahankan toleransi jaringan kulit terhadap tekanan tidak memberikan hasil maksimal. Upaya mempertahankan atau memperbaiki elastisitas jaringan kulit, mencegah kulit kering atau lembab berlebihan, dan menjaga kebersihan kulit mendukung intervensi pencegahan luka tekan secara maksimal.

Potter dan Perry (2005), menyatakan setelah kulit dibersihkan, gunakan pelembab untuk melindungi epidermis sebagai pelumas, tapi tidak boleh terlalu pekat. Jika klien mengalami inkontinensia atau mendapatkan makanan melalui sonde, sebaiknya klien selalu dibersihkan dan area yang terpapar cairan diberi lapisan pelembab sebagai pelindung.

Reddy, Gill, dan Roccon (2006) dalam Dealey (2009) merekomendasikan bahwa penanganan kulit kering pada sakrum secara khusus dengan menggunakan pelembab sederhana. Dijelaskan pula bahwa penting untuk memberikan pelembab secara teratur untuk mendapat keuntungan yang maksimal dan mengurangi lingkungan yang menyebabkan kulit kering dan berkurangnya kelembaban kulit seperti suhu dingin, 
Tabel 7. Distribusi Proporsi Responden Berdasarkan Kejadian Luka Tekan Grade I Non Blanchable Erytema

\begin{tabular}{llcccccc}
\hline \multirow{2}{*}{ Variabel } & \multirow{2}{*}{ Kategori } & \multicolumn{2}{c}{ Kelompok Intervensi } & \multicolumn{2}{c}{ Kelompok Kon trol } & \multicolumn{2}{c}{ Jumlah } \\
& & $\mathbf{n}$ & $\boldsymbol{\%}$ & $\mathbf{n}$ & $\boldsymbol{\%}$ & $\mathbf{n}$ & $\mathbf{\%}$ \\
\hline $\begin{array}{l}\text { Luka Tekan } \\
\text { Grade I }\end{array}$ & Terjadi & 0 & 0 & 4 & 26,67 & 4 & 12,12 \\
& Tidak Terjadi & 18 & 100 & 11 & 73.33 & 29 & 87,88 \\
\hline
\end{tabular}

dan hidrasi tidak adekuat. Kulit kering dapat meningkatkan risiko terbentuknya fissura dan rekahan stratum corneum. Penggunaan pelembab topikal memiliki manfaat untuk mempertahankan kelembaban kulit dan keutuhan stratum corneum dari paparan langsung.

Sifat-sifat topikal yang diharapkan tersebut ada pada $V C O$, kandungan zat-zat didalamnya mampu memberi nutrisi pada kulit dengan menjaga toleransi jaringan kulit terhadap tekanan, gesekan dan shear sebagai penyebab utama terbentuknya luka tekan. Hasil analisis multivariat penelitian juga menunjukkan bahwa efektifitas penggunaan $V C O$ dengan pijat dikontrol oleh Indeks Massa Tubuh.

\section{Kesimpulan}

Peneliti mengambil kesimpulan bahwa penggunaan Virgin Coconut Oil (VCO) dengan pijat, efektif untuk digunakan dalam pencegahan luka tekan grade I pada klien yang berisiko mengalami luka tekan di Rumah Sakit AB Provinsi Lampung dengan dikontrol oleh Indeks Massa Tubuh (IMT) klien.

Peneliti menyarankan kepada tim pelaksana asuhan keperawatan di ruang rawat agar menggunakan
$V C O$ dengan pijat dalam perawatan kulit untuk mencegah luka tekan. Selain itu, pencegahan juga dapat dilakukan dengan status nutrisi pada klien yang berisiko mengalami penurunan status nutrisi (TG, RS, NN).

\section{Referensi}

Agero, A.L., \& Verallo-Rowell, V.M. (2004). A randomized double-blind controlled trial comparing extra virgin coconut oil as a moisturizer for mild to moderate xerosis. Dermatitis, 15 (3), 109-116.

Amin, S. (2009). Cocopreneurship aneka peluang bisnis dari kelapa. Yogyakarta: Lily Publisher.

Ayello, E.A.P. (2007). Predicting pressure ulcer risk. Try this: Best practice in nursing care to older adult, 5. Diperoleh dari http://consult gerirn.org/uploads/File/trythis/issue05.pdf.

Bryant, R.A. (20007). Acute and chronic wounds nursing management (2nd Ed.). Missouri, St. Louis: Mosby Inc.

Ellis, J.R., \& Bentz, P.M. (2007). Modules for basic nursing skills (7th Ed., Vol. 1). Philadelpia: Williams \& Wilkins.

Tabel 8. Distribusi Kejadian Luka Tekan Grade I pada Responden yang Dirawat dengan VCO dan Tanpa VCO

\begin{tabular}{|c|c|c|c|c|c|c|c|c|}
\hline \multirow{3}{*}{ VCO } & \multicolumn{4}{|c|}{ Luka Tekan Grade I } & \multirow{2}{*}{\multicolumn{2}{|c|}{ Total }} & \multirow{3}{*}{$R R(95 \% C I)$} & \multirow{3}{*}{$\mathbf{p}$} \\
\hline & \multicolumn{2}{|c|}{ Tidak Terjadi } & \multicolumn{2}{|c|}{ Terjadi } & & & & \\
\hline & $\mathbf{n}$ & $\%$ & $\mathbf{n}$ & $\%$ & $\mathbf{n}$ & $\%$ & & \\
\hline Perawatan dg VCO & 18 & 100 & 0 & 0 & 18 & 100 & 0,733 & 0,033 \\
\hline Perawatan tanpa VCO & 11 & 73,3 & 4 & 26,7 & 15 & 100 & $(0,540-0,995)$ & \\
\hline Jumlah & 29 & 87,88 & 4 & 12 & 33 & 100 & & \\
\hline
\end{tabular}


Fitriyani, N. (2008). Pengaruh posisi inklin $30^{\circ}$ terhadap kejadian dekubitus pada pasien stroke di bangsal Anggrek I RSUD Dr. Moewardi Surakarta (Tesis master, tidak dipublikasikan). Fakultas IlmuKesehatan Keperawatan Universitas Muhammadiyah, Surakarta.

Gustia, I. (2009). Minyak kelapa sehat tanpa proses pemanasan. Diperoleh dari http://health.detik. com.

Lemeshow, S., et al. (1990). Besar sampel dalam penelitian kesehatan (Dibyo Pramono, Penerjemah). Yogyakarta: Gadjah Mada University Press.

Lucida, et al. (2008). Uji daya peningkat penetrasi virgin coconut oil (VCO) dalam basis krim. Jurnal Sains \& Teknologi Farmasi, 13 (1). Diperoleh dari http://ffarmasi.unand.ac.id/ pub/Publikasi \%20Sukma.pdf.

Lucida, Salman, \& Hervian. (2008). Pengaruh virgin coconut oil (VCO) di dalam basis krim terhadap penetrasi zat aktif. Diperoleh dari http://ffarmasi.unand.ac.id/pub/Publikasi $\% 20$ Sukma.pdf.

National Guideline Clearinghouse (NGC) \& Institute for Clinical Systems Improvement (ICSI). (2007). Skin safety protocol: Risk assessment and prevention of pressure ulcers. Diperoleh dari www.essentialevidence plus.com.

Ogbolu, D.O., Oni A.A., Daini, O.A., \& Oloko, A.P. (2007). In vitro antimicrobial properties of coconut oil on candida species in Ibadan, Nigeria. J Med Food, 10 (2), 3847.
Potter, P.A., \& Perry, A.G. (2005). Fundamental of nursing. USA: Mosby Inc.

Rajamohan, T., \& Kevin, K.G. (2010). Effect of topical application of virgin coconut oil on skin component and antioxidant status during dermal wound healing in young rats. Journal of Pharmacology \& Bhiophysical Research, 23 (6). Diperoleh dari http://content.kar ger.com/ProdukteDB/produkte.asp?Doi=313 516.

Reddy, M., Gill, S.S., \& Roccon, P.A. (2006). Preventing pressure ulcer: A systemic review. JAMA, 296 (8), 974-984.

Rest Haven. (2008). Pressure ulcer protocol. New York: Rest Haven.

Siswono. (2006). Manfaat minyak kelapa murni (VCO) untuk kesehatan. Diperoleh dari http:// www.republika.co.id.

Trevithick, J.R., \& Mitton, K.P. (1999). Uptake of vitamin $\mathrm{E}$ succinate by the skin, conversion to free vitamin $\mathrm{E}$, and transport to internal organs. Biochemical Molekul Biology International, 47 (3), 509-518.

Villariba, C.C. (2004). Virgin coconut oil wins the war of oils. Diperoleh dari http://www. coconut researchcenter.org/virgincoconutoil. htm.

Wang, X., \& Quinn, P.J. (1999). The effect of tocopherol on the thermotropic phase behaviour of dipalmitoylphos phatidylethanolamine: A synchrotron X-ray diffraction study. Eur $J$ Biochem, 264, 1-8. 